\title{
Increasing student interest by the use of interactive computer simulations
}

\author{
THOMAS RYWICK \\ State University of New York, College at Fredonia, Fredonia, New York 14063
}

\begin{abstract}
Two methods of increasing the involvement of introductory social psychology students with the topic of "person perception" were implemented and compared. Students either experienced two computer simulations of situations which illustrated person-perception principles or participated in a typical person-perception experiment. Students with computer experience, perhaps because of the individualized nature of the simulations, rated "person perception" as more interesting and more important than the experiment-participation students. Knowledge concerning person perception did not differ between groups.
\end{abstract}

In recent years, a number of investigators have been concerned with the processes by which we form impressions of other people, and textbooks have included person perception as an integral part of modern social psychology (Freedman, Carlsmith, \& Sears, 1974; Middlebrook, 1974). In spite of this interest, I have noticed that students in undergraduate social psychology courses report person perception to be one of the least interesting topics of the course.

An informal feedback from students indicated that students reacted very negatively to lectures concerning laboratory research on order effects in person perception which they considered highly artificial (Anderson, 1965, 1968). The reported research was concerned with the specification of conditions that influence people's reliance on earlier vs. later sequential information about a person when forming a general impression of that individual. Lectures also covered the theoretical possibilities of how memory storage related to person-perception order effects (Anderson \& Hubert, 1963; Rywick \& Schaye, 1974).

In an attempt to increase student interest in person perception while retaining in-depth coverage of the topic. the lectures were supplemented with opportunities for the students to have contact with situations that illustrated person perception principles and research. Two such opportunities for contact were compared in the present study: experience with interactive computer programs that simulated applications of order effect principles vs. participation as a subject in a typical order effects experiment.

\section{METHOD}

\section{Subjects}

Students in a sophomore social psychology class served as subjects. All subjects lacked experience with interactive computers. Twenty-tive students participated in a typical person-perception order effects experiment run by the instructor, and 19 students were

The development of the programs utilized in the present study was supported by National Science Foundation Grant GJ-33144 to the New York Educational Computer Consortium. taught by the instructor to use an IBM 2741 terminal and then worked through the two simulation programs described below. Students were assigned randomly to the two groups.

\section{Materials}

The programs relevant to this study are "Football" and "Impressions." They are written in APL and are stored in the public libraries of the State University of New York at Binghamton's IBM 370/155 time-sharing system. Four IBM 2741 terminals at SUNY. College at Fredonia, are wired directly to the Binghamton systen.

Football. This program consists of a 20 -min football game played against the computer. There are four offenses and three defenses that can be chosen, each combination of which has 15 potential outcomes probabilistically programmed to occur according to National Football League statisties. Except for the limited number of offensive and defensive strategies permitted, the game is fairly realistic, with oppostunities for punts, tield goals, safeties, etc., programmed into the game. The offenses utilized by the computer are such that one offense (randomly determined for each game) is used predominantly early in the game and another is used later in the contest. After the game, the user is questioned, by the computer. concerning his perceptions of the computer's offensive strategy. He is asked to specity which offense was used most often, and then (having been given the correct answer if necessary) he is asked to estinate the percentage of plays on which the computer used its most preterred offense. Gross over- or underestimation of this percentage is indicated to the student and is related to the computer's tendency to use different strategies early vs. late in the gatme. The nature of the order effects that the student's answers reveal (primacy vs. recency) is then explained to the student.

Impressions. This program presents the student with sets of adjectives, onte adjective at a time, with each ad jective crossed out as soon as it is presented. The eight sets of adjectives presented to each user are randomly created for each student from a pool of 90 adjectives. Four of the sets contain both positively and negatively craluated adjectives in randon order. The remaining four sets. however. are ordered sets with three positive adjectives followed by three negative. or three negative followed by three positive. The program instructs the user to rate each set of adjectives on a 7-point scale of hou likable a person described by the adjectives in the set would he. This program therefore presents adjective descriptions to the computer user much like an experimenter presents subjects with adjective descriptions in al typical order effects experiment (Rywick. 1971). The students ratings are stored and then analyzed by the computer. The user's reliance on the earlier vs. later information in the ordered sets is then explained to the user. Data from all users are stored and easily retrieved by the instructor.

The adfective sets presented to students in the experimentparticipation condition were virtually identical to the sets created by the computer in the computer-experience condition. 
Table 1

Rating and Answer Data and Data Analyses

\begin{tabular}{lcccc}
\hline & $\begin{array}{c}\text { Com- } \\
\text { puter } \\
\text { Group }\end{array}$ & $\begin{array}{c}\text { Experi- } \\
\text { ment } \\
\text { Group }\end{array}$ & $t^{*}$ & $\mathrm{p}$ \\
\hline $\begin{array}{l}\text { Rating of interest } \\
\text { Rating of importance } \\
\text { to society }\end{array}$ & 6.05 & 5.00 & 4.11 & $<.01$ \\
$\begin{array}{l}\text { Rating of importance } \\
\text { to social psychology }\end{array}$ & 5.90 & 5.34 & 2.63 & $<.05$ \\
$\begin{array}{l}\text { Number of correct } \\
\text { answers }\end{array}$ & 3.68 & 5.28 & 2.28 & $<.05$ \\
\hline
\end{tabular}

*All $t$ tests had $d f=42$.

\section{Procedure}

Subjects were scheduled to meet their instructor in groups of three. The meetings took place over a 3 -day period in either the computer room (for the computer experience group) or the instructor's social psychology laboratory (for the experimentparticipation group). Meetings at the two locations were determined randomly, except that the computer room became unavailable for the last two meetings scheduled for the computer conditions, so these were held at the social psychology laboratory instead.

Students in the computer condition were given a brief (about 5-min) introduction to using a computer terminal, including how to sign on, call for programs, and how to interact with the computer. They were then given the names of the two programs used in this study and told to work through the two programs. The instructor stayed for a few minutes to assure himself that the students knew how to proceed. Each student, working individually at a terminal, worked through the programs with 10 students using "Football" first and nine using "Impressions" first. Subjects were instructed to take the printouts of their terminal sessions and bring them to class.

Students in the experiment-participation condition took part in a typical person-perception study that took about $10 \mathrm{~min}$ to complete. These students were verbally presented, by the instructor, with eight sets of adjectives, six adjectives in each set. Students were instructed to rate these sets for likableness, much like the task in "Impressions." A brief description of the "order effects" nature of the experiment was given to subjects.

During class periods, 2 to 7 days after the subjects' computer experience or their participation in the experiment, lectures concerning person perception were presented in class. Included were extensive comments on order effects research. One and a half weeks later, a regularly scheduled exam, covering person perception and two other topics, was held. Attached to the exam was an eight-item questionnaire concerning person perception which all students filled out. Three items included 8-point rating scales requesting that students comment concerning their attitudes about person perception, i.e., interest level, importance for society, and importance for social psychology. The other five items were factual multiple-choice questions based on person-perception material in the students' text. None of the factual questions concerned the specific procedures used in either the computer or experiment-participation conditions.

\section{RESULTS AND DISCUSSION}

Since a group who experienced only the instructor's lectures on person perception but not supplementary experience was not employed, the success of the computer and experiment-participation experiences in promoting interest and knowledge above the level produced by lectures alone cannot be ascertained. The data of this study are useful only for comparing the relative effectiveness of the two conditions noted.

The mean attitude ratings, the mean number of correct answers to the factual questions, and the $t$ values obtained from comparisons of the two experimental groups on all measures appear in Table 1. All attitude ratings were significantly different, such that students with the computer experience rated "person perception" more interesting and more important than the experimentparticipation students. Neither group exhibited significantly superior knowledge of the topic, although the factual-question data may not reflect certain differences in knowledge between the groups that may have existed; it could be that detailed knowledge or memory of order effects research may differ but that the process was not tapped by the general questions included in the questionnaire.

Assuming that experimenter bias did not occur and that the computer group's greater interest in person perception was valid, the generality of this finding, and therefore the applicability of this knowledge to other situations, is still questionable. What is needed is replication of this experiment using a number of different instructors and a variety of computer programs on a variety of topics. Consistent superiority of the computer simulation experience would, of course, provide strong rationale for the continued use of such experiences. An increasing number of interactive computer programs, including many simulation programs, now exist on the SUNY Binghamton system and could easily be used in such replications.

Easy-to-use computer simulations seem to provide the opportunity for individualized student involvement in topics that might normally be lacking in many courses. The particular advantages of computer simulation include (1) flexibility in student scheduling. (2) nonnecessity of the instructor's (experimenter's) continual presence, and (3) the student's perception that the simulation was individualized, i.e., that other students' experiences were somewhat different.

\section{REFERENCES}

Anderson, N. H. Primacy effects in personality impression formation using a generalized order effect paradigm. Journal of Personality and Social Psychology, 1965, 2, 1-9.

ANDERSON, N. H. Application of a linear-serial model to a personality-impression task using serial presentation. Journal of Personality and Social Psychology, 1968, 10, 354-362.

ANDERSON, N. H., \& Hubert, S. Effects of concomitant verbal recall on order effects in personality impression formation. Journal of Verbal Learning and Verbal Behavior, 1963, 2, 379-391.

Freedman, J. L., Carlsmith, J. M., \& Sears, D. O. Social psychology (2nd ed.). Englewood Cliffs, N.J: Prentice-Hall, 1974.

Middlebroox, P. N. Social psychology and modern life. New York: Knopf, 1974.

Rywick, T. Primacy effects in impression formation as a function of type of impression. Psychonomic Science, 1971, 25, 195-196.

Rywick, T., \& SChaye, P. Use of long-term memory in impression formation. Psychological Reports. 1974, 34, 939-945. 